\title{
Profile Interview: Prof. Rob Moodie
}

\author{
"Get up. Do good. Be good. Be."
}

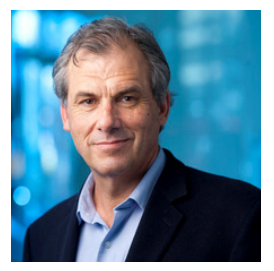

\section{Fanuel Bickton talks to Rob Moodie on his public health career in noncommunicable diseases}

FB: Brief me on your personal and professional background.

RM: I was born in 1953 in Melbourne, Australia. I studied medicine at the University of Melbourne in Australia. Later I trained in tropical medicine at the University of Paris in France, in general practice in Australia and in public health at Harvard University in the US.

My first job as a doctor was in a rural hospital in Australia for a year. I was very restless, so I moved to Paris to work at the American Hospital there. After Paris I moved to Gedaref in eastern Sudan for a couple of years to work with the Save the Childre Fund in mother and child clinics in camps set up for Tigrean and Eritrean refugees. Following my second bout of hepatitis in six months I went back to Melbourne to do pediatrics at the Royal Children Hospital. I realised that I wasn't cut out to be a pediatrician so I moved to Alice Springs in central Australia to work for Congress an Aboriginal Community Controlled Health Service for five years. During this time I married Annie, a physiotherapist. We went back to study in France and I again ended up in the Sudan, this time with Medicins sans Frontieres (MSF). That's when I moved from a combination of clinical medicine and public health to full-time public health. Our two children Nick and Penny were born in Alice Springs - this was the mid-1980s which marked the emergence of the AIDS epidemic. I had the opportunity of working for the Global Program on AIDS in the Pacific, Cameroon and Geneva, with inspirational public health leaders such as Jonathan Mann and Daniel Tarantola. We moved back to Melbourne where I worked in the HIV and AIDS group in the health department. We did move around a lot!

In 1990 a scholarship enabled us to move to Boston where I did my Master of Public Health. It was a fascinating time as we put together a team of Harvard law students and public health students to visit Iraq straight after the end of the first Gulf War to determine the impact of war on the under five population in Iraq. Instead of heading back to Melbourne we spent 5 months in Uganda working for WHO carrying out a 1000 household survey to understand the impact of national information, education and communication (IEC) campaigns on sexual behaviours.

Back to Melbourne again where I helped establish the Burnet Institute's international health group. This was followed by an exciting invitation to join UNAIDS in Geneva, right at its inception. My role was as the first Director of Country Programmes; a job I found very challenging! To be honest I am not sure I did a very good job, as I lacked the leadership and management skills, which is why I've now become very interested in teaching them.

We were starting to slow down our moves by then and we came back to Melbourne where I spent the next nine years as the CEO of the Victorian Health Promotion Foundation (VicHealth). It is the world's first health promotion foundation to use a tax on tobacco to buy out and replace tobacco industry sponsorship in sports and the arts, and to fund tobacco control programs and health promotion research. Then I moved to the University of Melbourne's Nossal Institute. Two years ago I came to Malawi.

\section{FB: How did you develop your public health interest in noncommunicable diseases (NCDs)?}

RM: Well, the health promotion foundation I worked with when I moved back from Geneva to Australia was all about NCDs. I became really interested in tobacco control and the problems of tobacco globally, as well as alcohol, drugs, poor diet, lack of physical activity, and poor mental health. I was very interested in ensuring the effectiveness of our investments in research, good health promotion, and upstream interventions. Our aim was to invest resources in the prevention of problems and promotion of good health our aim was to be the 'fence at the top of the cliff', not just the 'ambulance at the bottom of the cliff'.

\section{FB: What challenges do you experience or see in the fight against NCDs?}

RM: The tobacco, junk food and alcohol companies are the major problems - as they have become the vectors of NCDS - and they lack any ethical foundation. In particular the tobacco industry (Big Tobacco) continues to promote a product they know is highly addictive and kills over half of the people who use it as directed. These unhealthy industries are working against health, whilst masquerading as being "part of the solution". I remember when I was asked by the Minister of Health in Australia to chair the National Preventive Health Taskforce specifically to look at the burden of obesity, tobacco and alcohol in Australia and how we can reduce the burden. We worked for eighteen months to develop a national strategy and we faced enormous opposition from tobacco companies when we recommended that the government greatly increase the cost of cigarettes and introduce 'plain packaging' - which is where you don't have any advertising on the pack apart from images of what damage it does. Big Tobacco hated this because the cigarette pack had become their last avenue for advertising.

\section{FB: How did you find yourself working in Malawi and what are your job experiences here?}

RM: As I've indicated, I have worked in this part of the world before, and I was keen to come back. At first, I wasn't quite sure where I would be of use so I talked to Steve Graham who is a Professor of Pediatrics who had worked in Maalwi for twelve years; he taught people like Ken Maleta and Kamija Phiri and he directed me to them. So I came to volunteer, asked if I could help and now here I am. I have been working as the MPH tutor, helping students get their Master of Public Health. 
FB: What is your personal impression on the health system in Malawi, in general, and on NCDs in particular?

RM: There is a very huge strain on the health resources in Malawi. There are of course major health problems in Australia and in other high income countries but they have much higher levels of resources to deal with them. But here we have an exponentially bigger gap between the health problems and the resources to deal with them. For example, the problems that the health system deals with require much higher workforce levels than are currently available. This is also why in terms of my teaching I am focusing on leadership and management skills, because in the health profession we normally teach technical skills, but we don't teach students how best to use those skills, for example in how to run a large hospital or department. Public health training (and medical and nursing training) should include training in management and leadership skills as much as it includes epidemiology, biostatistics or clicnal skills. This is why we have been running workshops on this topic with nurses here at Queens and with the Obstetrics department at $\mathrm{KCH}$ in Lilongwe. I've learned an enoumus amount from being involved in the workshops. And we plan to follow them up over several years to help them to continually and consistently develop their management and leadership skills. Talking of NCDs, it's a nascent issue here, with people just realizing how important it is. On the other hand, Malawi has an enormous number of competing challenges which take a large portion of time and effort, such as malnutrition, HIV, malaria, TB, childhood pneumonia, diarrhea, high fertility rates and high levels of maternal mortality. The major NCDs are hypertension and diabetes in the first instance. As the country develops it is likely that preventable cancers will increase in addition to the challenges of poor diet and obesity. So that is why it is important to deal with these challenges now rather than later. Another significant health issue in Malawi is injury prevention - particularly road trauma. For example, it seems so many people have lost friends to road trauma, but as a public health issue there is virtually nothing spoken or researched about it. So many of the deaths on the road are preventable. So maybe it's time that we talk about managing it by, for example, working with different stakeholders such as the police, engineers, minibus drivers - so that the roads can be much, much safer.

\section{FB: What should be done in Malawi to succeed in} combatting NCDs?

RM: There should be acknowledgment of these serious issues and that they are largely preventable. There should be adequate systems in place for managing people with high blood pressure and diabetes. Then there are preventive measures that we need to institute now: reducing salt intake, avoiding smoking, and making sure that alcohol consumption is at levels that are as safe as possible. We should also increase research efforts in NCDs with an emphasis on responsiveness of the health systems in the prevention and management of NCDs.

\section{FB: What accomplishments are you most proud of in the fight against NCDs?}

RM: Chairing the national preventive health taskforce in Australia which really drove a major change in plain packaging and in increasing taxation on tobacco, recognized globally as the most successful way of decreasing tobacco consumption.
I am really proud to have played a part in that. Today, Australia has one of the lowest tobacco smoking rates in the world. I am also proud to have contributed to promoting good mental health. At VicHealth we established one of the first mental health promotion plans, promoting social connection, freedom from discrimination or stigmatization, and high levels of social support.

FB: What lessons can you give a junior colleague who might be embarking on a career similar to yours, that is, a public health career in NCDs?

RM: Talk to and make connections with people you admire. Ask them for advice. Be inspired by them and make sure you have mentors who can give you guidance and support.. These are some of the ways of following where you want to go.

\section{FB: What are your current or future research or work interests?}

RM: I am actually not a researcher; I am personally not really interested in generating 'new' knowledge. Rather, I am really interested in the application of existing knowledge, because so much of what we know doesn't get implemented. So I am trying to apply what we already know. As mentioned before, my current focus has been around teaching leadership skills; this is about communication, planning, problem solving, decision-making, networking, time management, selfawareness, managing people, negotiating mentoring etc. These are the skills we need to operate most effectively.

\section{FB: Where do you see yourself in the next 5 years from} now?

RM: Great question. I want to be alive. I want to continue working in public health and to continue working here. I love working with students. I enjoy mentoring and supporting people. I would like to be a better person than I am now, so I want to constantly learn to be less egotistical and to be more generous.

\section{FB: What is your motto?}

RM: Get up. Do good. Be good. Be. 'Get up' means you have to be active, and really commit to your work and life. 'Do good' means you have to be good at your job. 'Be good' means you have to be a good global citizen. 'Be' means you have to be mindful, be 'in the present' as a way of maitaining good emotional health as well as being mindful of family and friends.

\section{FB: Any closing remarks?}

RM: I love my work. I feel privileged to have been able to work as a doctor and as a public health physician. I have learned so much from working in different communities and countries and it's a privilege to come and work here in Malawi. 